This item was submitted to Loughborough's Research Repository by the author.

Items in Figshare are protected by copyright, with all rights reserved, unless otherwise indicated.

\title{
Analysis of the hygrothermal functional properties of stabilised rammed earth materials
}

PLEASE CITE THE PUBLISHED VERSION

http://dx.doi.org/10.1016/j.buildenv.2009.01.007

PUBLISHER

(C) Elsevier Ltd.

VERSION

AM (Accepted Manuscript)

LICENCE

CC BY-NC-ND 4.0

\section{REPOSITORY RECORD}

Hall, Matthew, and David Allinson. 2019. "Analysis of the Hygrothermal Functional Properties of Stabilised Rammed Earth Materials". figshare. https://hdl.handle.net/2134/11833. 
This item was submitted to Loughborough's Institutional Repository (https://dspace.lboro.ac.uk/) by the author and is made available under the following Creative Commons Licence conditions.

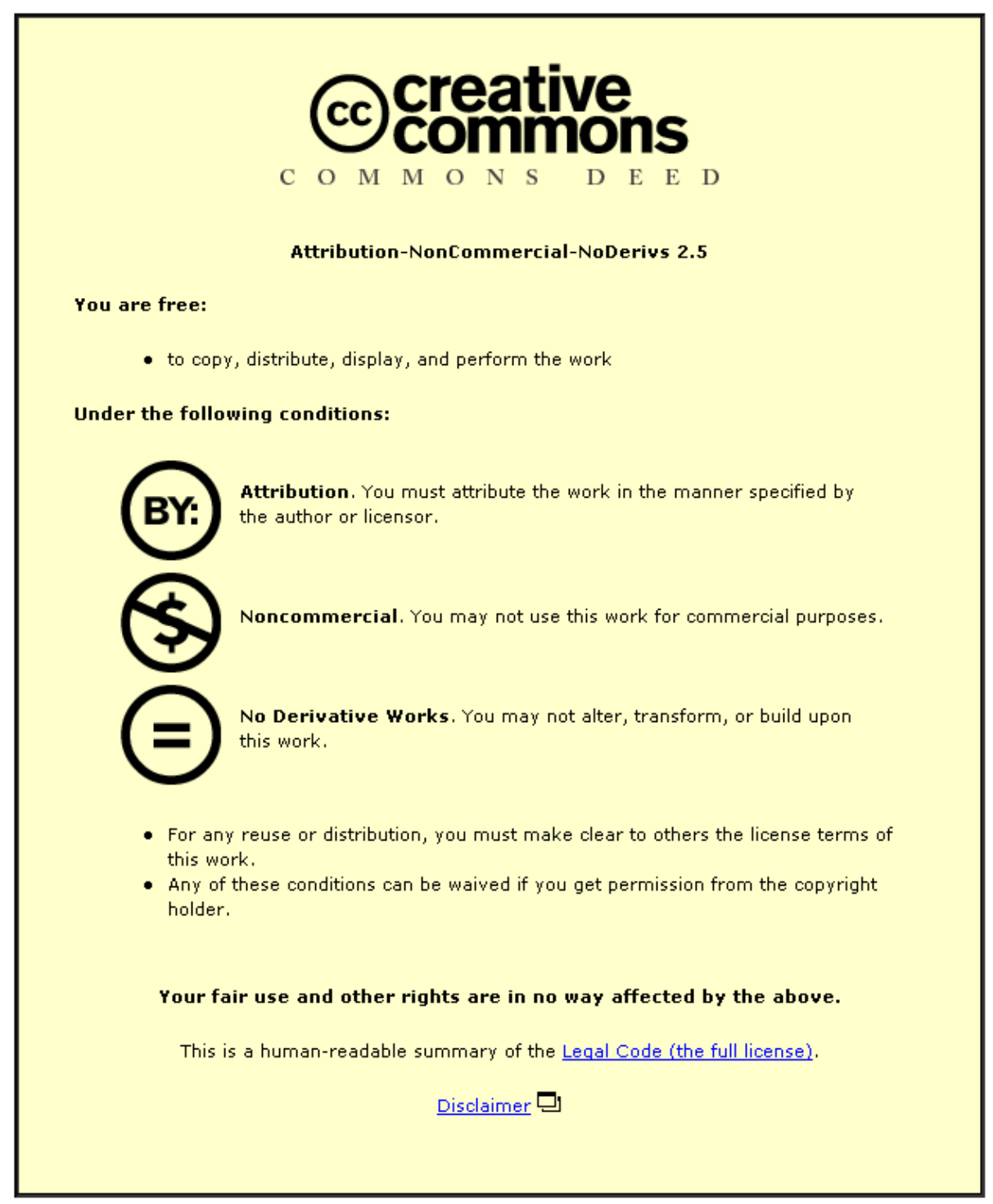

For the full text of this licence, please go to: http://creativecommons.org/licenses/by-nc-nd/2.5/ 
Analysis of the Hygrothermal Functional Properties of Stabilised Rammed Earth Materials

\section{Matthew Hall* and David Allinson}

Institute of Sustainable Energy Technology, School of the Built Environment, University of

Nottingham, University Park, Nottingham NG7 2RD, UK Tel: +44 (0) 115846 7873, Fax:

+44 (0) 115951 3159, E-mail: matthew.hall@nottingham.ac.uk

*corresponding author

\section{Abstract}

Suitable experimental methodologies for determining the hygrothermal properties of stabilised rammed earth (SRE) materials have been presented along with comparative experimental data for three different SRE mix designs with parametric analysis of the influence of these variables on material function. Higher bulk porosity corresponds to reduced volumetric heat capacity $(C)$, but increased sorptivity $(S)$ and vapour permeance $(W)$. Since bulk porosity and void size distribution (VSD) are interdependent variables, it follows that for constant particle size distribution (PSD) and compaction energy an increase in porosity results in an increase in the mean pore radius, $\bar{r}$ for a material. This explains why the magnitude of liquid/vapour transfer ( $S$ and $W$ ) terms are inversely related to the hygroscopic moisture capacity, $\xi$ since the capillary potential, $\Psi$ will increase when the mean pore diameter decreases. The implications are that the hygrothermal properties of SRE materials can be designed and predicted by manipulating particle size distribution and compaction energy.

Keywords: hygrothermal; porous materials; stabilised rammed earth; heat \& mass transfer and storage 
Nomenclature:

$28 \quad V_{\mathrm{T}}=$ total volume

$29 \quad V_{s}=$ volume of solid

$30 \quad V_{v}=$ volume of void

$31 \quad V_{a}=$ volume of air

$32 V_{m}=$ molar volume

$33 p_{v}=$ vapour pressure

$34 \quad p_{\text {sat }}=$ saturation vapour pressure

$35 p_{\text {sat }} *=$ saturation vapour pressure above a flat surface

$36 \quad P_{a}=$ total air pressure

$37 \quad P_{w}=$ total water pressure

$38 \quad r=$ pore radius

$39 \quad r_{c r i t}=$ critical pore radius

$40 \quad \bar{r}=$ mean pore radius

$41 \quad T=$ thermodynamic temperature (K)

$42 \eta=$ viscosity

$43 \gamma=$ surface tension

$44 \varphi=$ relative humidity $(0 \leq \varphi \leq 1)$

$45 \mathrm{RH}=$ relative humidity $\%\left(\varphi^{*} 100\right)$

$46 \theta=$ relative moisture $(0 \leq \theta \leq 1)$

$47 \quad \theta_{r}=$ residual moisture content

$48 \theta_{c}=$ capillary saturation moisture content

$49 \theta_{A E V}=$ air entry value moisture content

$50 \quad \theta_{s}=$ saturation moisture content

$51 \rho_{w}=$ density of water $\left(\mathrm{kg} / \mathrm{m}^{3}\right)$ 
$\rho_{v}=$ density of water vapour $\left(\mathrm{kg} / \mathrm{m}^{3}\right)$

$g=$ gravitational constant

$h=$ height

$g_{v, \text { air }}=$ rate of water vapour diffusion through air

$D=$ diffusion coefficient for water vapour in still air $\left(\mathrm{m}^{2} / \mathrm{s}\right)$

$C_{v}=$ mass concentration of water vapour $\left(\mathrm{kg} / \mathrm{m}^{3}\right)$

$M_{w}=$ molar mass of water $(\mathrm{kg} / \mathrm{kg} \mathrm{mol})$

$R_{o}=$ the universal gas constant $(\mathrm{J} / \mathrm{kg} \mathrm{mol} \mathrm{K})$

$m_{w}=$ mass of water $(\mathrm{kg})$

$A=$ area

$G$ = water vapour flow rate $(\mathrm{kg} / \mathrm{s})$

$W=$ water vapour permeance $\left(\mathrm{kg} / \mathrm{m}^{2} \mathrm{~s} \mathrm{~Pa}\right)$

$i=$ cumulative volume of absorbed water per unit inflow surface area $\left(\mathrm{mm}^{3} / \mathrm{mm}^{2}\right)$

$t=$ time

$S=$ sorptivity $\left(\mathrm{mm} / \mathrm{min}^{-0.5}\right)$

$\xi=$ hygroscopic moisture storage function

$\Psi=$ capillary potential

$\lambda=$ thermal conductivity $(\mathrm{W} / \mathrm{m} \mathrm{K})$

$\lambda^{*}=$ moisture content-dependent thermal conductivity (W/m K)

$q_{\text {sens }}=$ sensible heat flow $\left(\mathrm{W} / \mathrm{m}^{2}\right)$

$q_{\text {lat }}=$ latent heat flow $\left(\mathrm{W} / \mathrm{m}^{2}\right)$

$w=$ reference moisture content $\left(\mathrm{kg} / \mathrm{m}^{3}\right)$

$g_{v}=$ rate of water vapour transfer $\left(\mathrm{kg} / \mathrm{s} \mathrm{m}^{2}\right)$

$h_{e}=$ specific latent enthalpy of evaporation/condensation $(\mathrm{J} / \mathrm{kg})$

$S_{r}=$ degree of saturation (or saturation ratio)

$m_{f}=$ moisture factor 
$c_{p}=$ specific heat capacity at constant pressure $(\mathrm{J} / \mathrm{kg} \mathrm{K})$

$c_{p}{ }^{*}=$ moisture content-dependant specific heat capacity at constant pressure $(\mathrm{J} / \mathrm{kg} \mathrm{K})$

$\varpi=$ relative mass fraction

\section{$1 \quad$ Introduction}

Approximately one half of the world's population are said to live or work in an earth building [1] and it has long been mooted that earth materials have the ability to provide superior levels of indoor thermal comfort, e.g. [2, 3, 4]. Stabilised rammed earth (SRE) is the modern practice of a traditional construction technique and is typically achieved by the addition of $\leq 10 \%$ Portland cement to subsoil and dynamic compaction (ramming) of the mixture into temporary formwork. It provides a low embodied energy material for rapid construction on-site. Its modern day use is widespread across Australasia, North America, Asia, and parts of mainland Europe such as Spain, Germany and France and increasingly Great Britain. Since earth is a porous, hygroscopic material that contains active clay minerals, it is expected that the walls absorb water vapour from the air when relative humidity increases and release this moisture when the humidity falls. As it is usual practice to leave earth walls exposed to the interior of the building, the availability of combined thermal and hygric buffering (i.e. passive air conditioning) will be maximised when compared with other materials such as brick, timber or concrete that are often covered over with more insulating and less permeable coverings, e.g. varnish and paints.

The functional properties of SRE that can be used to describe its hygrothermal behaviour are the moisture storage function, vapour permeability, liquid conductivity, thermal conductivity, and specific heat capacity. Samples of three SRE mix designs were manufactured and tested to determine these functional properties and the results compared.

The objective of this paper is to investigate how the hygrothermal properties of SRE materials can be experimentally measured and how these functional properties are influenced by the 
variable mix design parameters of the material. The aim is to test the hypothesis that hygrothermal properties can then be predicted and designed through correspondence with mix design parameters. SRE materials can be characterised as multiphase granular composites whose particle size distribution (PSD) and particle packing efficiency largely determine the geometry of their matric structure. The term stabilisation refers to the application of a process and/or additive component that enhances the cohesion, Young's modulus or another physical property [5-7]. By far the most common forms of stabilisation are i) dynamic compaction and ii) addition of hydraulic binders, e.g. cementicious materials. As with most granular soils, dynamic compaction close to the Proctor optimum moisture content increases the inter particle friction/interlock whilst reducing the bulk porosity. The addition of hydraulic binders (commonly $\leq 10 \%$ Portland cement) increases the internal cohesion of the material and enhances durability and toughness [5-9]. Since hardened cement paste bonds particles together by surface adhesion between the paste and particle surfaces (interfacial transition zone), cement stabilisation is most effective on granular soils [8-10] where the specific surface area per unit mass is lower and the greater absence of cohesive materials is less able to interfere with the interfacial transition zone.

\section{Specimen Preparation}

The characterisation of SRE material composition can easily be approximated using the geotechnical soil model. The particle size distribution for SRE must normally fall within designated upper and lower limits resulting in a wide range of achievable particle packing efficiencies and associated bulk porosity/dry density and void size distribution (VSD), as explained extensively in the authors’ previous research [11-13]. By using an established technique of blending characterised soil constituents (14-6.3mm gravel, $5 \mathrm{~mm}$ down medium grit sand, silty clay) and matching the net PSD to the defined upper/lower limits, the authors can maintain the parameters of aggregate mineralogy, particle angularity and clay mineralogy 
as constants whilst keeping PSD as the single variable. SRE specimens were prepared as one litre cylinders (3 compaction layers), 1/3 litre discs (1 compaction layer), and 300 x 300mm slabs (1 compaction layer). All were stabilised by compacting at OMC using a constant energy of $596 \mathrm{~kJ} / \mathrm{m}^{3}$ and the addition of 6\% wt CEM IIa class Portland cement, followed by air curing for a minimum of 28 days at $20^{\circ} \mathrm{C}\left( \pm 2^{\circ} \mathrm{C}\right)$ and $75 \% \mathrm{RH}( \pm 5 \%)$ in an environmental chamber.

\section{$3 \quad$ Moisture Sorption and Storage}

The assumption here for hygrothermal materials is that a representative microstructure of porous media has a total volume $\left(V_{T}\right)$ which consists of solid state matter $\left(V_{S}\right)$ and fluid-filled void $\left(V_{v}\right)$, where $V_{T}=V_{s}+V_{v}$. Under atmospheric conditions, when the material is dry the voids are filled with air $\left(V_{v}=V_{a}\right)$ and when saturated the voids are filled with water $\left(V_{v}=V_{w}\right)$. Clearly, when moisture enters a dry or unsaturated continuum it must displace air from the moment it crosses the boundaries defined by $V_{T}$; a process referred to as 'absorption'. Absorbed moisture vapour may also be 'adsorbed' to the internal surfaces by van der Waals forces. Absorbed moisture may be classified into one of three domains (hygroscopic, capillary, and gravitational) depending upon i) its phase when it enters $V_{T}$, and ii) its strength of electrostatic attraction. Hygroscopic moisture is absorbed in the vapour phase, capillary moisture is absorbed in the liquid phase, and gravitational moisture is liquid that is absorbed when the capillary potential in the pore network is zero (i.e. super saturation).

Although the classification of absorbed moisture (determined by its phase upon entry) cannot change, its phase once inside $V_{T}$ can change, e.g. condensing from vapour to liquid. This is chiefly governed by internal void geometry and electrostatic surface charge for a given temperature and partial vapour pressure. Theoretically, the saturation vapour pressure above a flat surface of liquid water ( $p_{\text {sat }}{ }^{*}$, when $r=\infty$ ) is dependent upon the pressure applied $\left(\Delta P_{a}\right)$ to 
that liquid by a surrounding gas, in this case air. For a given $\Delta P_{a}$, the saturation vapour pressure becomes $p_{\text {sat }}=p_{\text {sat }} * e^{V_{m} \Delta P / R_{o} T}$ [14]. Furthermore, by curving the surface of the water to a known radius, $r$ a pressure change (negative for water) occurs where $\Delta p_{\text {sat }}=2 \gamma / r$. Therefore, we can see that the saturation vapour pressure of liquid water held inside a pore of radius $r$ (and having a contact angle $\alpha$ ) is greater than that of a flat surface, i.e. $p_{\text {sat }}>p_{\text {sat }}{ }^{*}$.

This of course leads to Kelvin's Equation, $p_{\text {sat }}=p_{\text {sat }}{ }^{*} e^{-2 \mathcal{W}_{m} / r R_{0} T}$ where molar volume of water $\sim 18 \mathrm{ml}$ at STP [14]. In the case of hygroscopic moisture (vapour phase) of known partial pressure, $p_{v}$ that has been absorbed by a pore, Kelvin's equation can simply be rearranged to find the 'critical pore radius' $\left(r_{c r i t}\right)$ assuming $p_{v}=p_{\text {sat }}$. At this point moisture vapour condenses inside the pore to restore thermodynamic equilibrium. Obviously, where radii vary within complex pore structures it follows that vapour condenses to fill the pore with liquid when $r<$ $r_{\text {crit, }}$ and visa versa.

Figure 1 shows the wetting/drying sorption isotherms for a typical hygrothermal material, correlating relative moisture content, $\theta$ with absorbed moisture domains. As with liquid sorption, hysteresis typically occurs between the relative moisture content, $\theta$ at a given humidity, $\varphi$ due to the influence of electrostatic potential on the porous material inside surfaces. As relative humidity increases from zero, single layer adsorption and then multi layer adsorption of water vapour molecules occurs within the pore structure of the material. Metastable groups of adsorbed water vapour molecules can spontaneously nucleate into a liquid water meniscus that is in equilibrium with the relative humidity for a given pore radius, as predicted by the Kelvin equation. In this way, hygroscopic moisture can be stored in liquid phase inside the porous material. Kelvin's equation can be used to calculate the theoretical critical pore radius in which water vapour condenses in relation to the relative humidity. The validity of Kelvin's equation applies to the portion of a sorption isotherm where capillary condensation will occur in pore radii sufficient to permit thicknesses greater than multi 
molecular layers, i.e. droplets. This typically occurs at $\varphi \approx 0.5$, although the occurrence of capillary potential-induced liquid moisture flow is typically not considered until $\varphi>0.8$ [15] (refer to value $\theta_{80}$, Figure 1). At the hypothetical point when $\varphi \rightarrow 1$, the transition from hygroscopic to capillary domain occurs and is defined as the residual moisture content, $\theta_{r}$. For modelling purposes, however, a 'kick point' moisture content can be specified to indicate the maximum hygroscopic moisture content since that can be readily determined experimentally, e.g. normally 95 or $98 \%$ RH $[15,16]$. Above this level pressure plate apparatus can be used for relative humidity at saturation. When $\theta$ is in the capillary domain, moisture transport is dominated by capillary potential, $\Psi$ and the microstructure is referred to as 'unsaturated' (as in soil mechanics), refer to Figure 2. During wetting, absorption will continue until capillary saturation $\theta_{c}$ at which point the ambient air pressure $P_{w}=P_{a}-\left(2 \gamma / r+\rho_{w} g h\right)$, for the supported mass of water inside the pore structure (where g is the gravitational constant) [14]. Obviously, if $\theta_{c}<<\theta_{s}$ (fully saturated) then additional moisture can be absorbed without capillarity (e.g. pressure differential, gravity etc), some of which can be supported by remaining net surface charge in the pore network surfaces. Thus, on the drying curve the maximum capillary moisture content is determined by the air entry value to find $\theta_{A E V}$. At 'super saturation' ( $>\theta_{A E V}$ ) the force of gravity on the additional mass of the non-capillary (or gravitational) moisture is greater than the attraction of the remaining net surface charge inside the pore structure.

The sorption and desorption isotherms were determined for representative samples of each rammed earth mix recipe. SRE disc specimens were split into large fragments $\left(V_{T} \approx 15 \mathrm{ml}\right)$ and oven dried to constant mass at $105^{\circ} \mathrm{C}$. An array of five sealed desiccators was prepared, each containing a different saturated salt solution and stored at an ambient air temperature of $23^{\circ} \mathrm{C} \pm 0.5^{\circ} \mathrm{C}$ in order to provide a wide range of stable relative humidity environments (see Table 1). The dry specimens were progressively placed in each of the desiccators, in order of 
increasing humidity, and permitted to absorb moisture vapour until constant mass was achieved (normally $>3$ days), defined as $<0.1 \% \Delta w t /$ day [17]. Samples were then fully immersed in distilled water for 24 hours and the saturated mass recorded to find $\theta_{c}$, but $\theta_{r}$ can

only be interpolated since it occurs at $\varphi \rightarrow 1$. The capillary saturated specimens were then progressively placed in each of the desiccators in order of decreasing humidity. In this manner both the sorption and desorption isotherms were determined. The relationship between the moisture content of a porous material and the relative humidity of the surrounding environment is described by the moisture storage function (MSF). It is used to calculate the partial pressure of a water vapour gradient for water vapour diffusion as well as the capillary potential gradient for liquid water conductivity (see part 1).

\section{$4 \quad$ Water Vapour Transport}

It is apparent that the fluid transport mechanism in porous materials is not simply defined by its domain classification. Once fluid has entered the porous medium $V_{T}$, the intrinsic conditions of the pore network will determine i) fluid phase, and ii) its associated transport mechanism(s). To elucidate, absorbed hygroscopic moisture (from vapour) will subsequently be adsorbed by internal surfaces, condense, or diffuse. Absorbed capillary moisture (from liquid) will either flow or vaporise. The intrinsic properties that determine these conditions include pore radius, pore geometry, surface charge, and surface temperature.

Water vapour can enter porous materials through pore openings at the surface and liquid water inside the material can evaporate. The material's granular skeleton reduces the available cross-sectional area of air for vapour diffusion and the complex spatial connectivity of the pore spaces increases path lengths, providing additional resistance. For pores with smaller diameter, the mean molecular free path of the water vapour molecules approaches or exceeds the pore diameter. In this case, pore wall collisions and van der Waals forces between the water vapour and pore surface dominate molecular movement, i.e. Knudsen diffusion. Also, water vapour molecules that are adsorbed to the walls of the 
pores inside the material, either in a single layer or as multiple layers, can move along the surface by surface diffusion. These phenomena are illustrated in Figure 3.

The rate of water vapour diffusion in still air can be described by Fick’s law:

$$
g_{v, a i r}=-D \frac{\partial C_{v}}{\partial x}
$$

This equation can be expressed in terms of water vapour partial pressure using the ideal gas law:

$$
C_{v}=\rho_{v}=\frac{p_{v} M_{w}}{R_{o} T}
$$

The rate of water vapour flow through a porous specimen can be determined using the wet 


\section{Liquid Water Transport}

Previous research has shown that bricks, stone, and SRE materials have been found to obey the $i / t^{0.5}$ linearity rule demonstrating dependence upon the $\gamma / \eta^{0.5}$ relationship [13, 19-21], i.e. capillary potential is the motivational force for flow in the unsaturated state. Theoretically, the sharp wet front approximation can be used to model absorption and desorption of capillary moisture and the associated transfer rates $[13,20]$. Experimentally, the gravimetric measurement of absorbed volume per unit inflow surface area, $i\left(\mathrm{~mm}^{3} / \mathrm{mm}^{2}\right)$ is measured using test specimens that are partially immersed to a constant a depth of $5 \mathrm{~mm} \pm 1 \mathrm{~mm}$. Pre-test conditioning and actual testing of the specimens were performed by the authors in a large environmental chamber at $23^{\circ} \mathrm{C} \pm 1^{\circ} \mathrm{C}$ and $50 \% \pm 5 \%$ relative humidity. In SRE materials, increasing the cementicious binder content resulted in an increase in bulk porosity and hence an increase in the sorptivity, $S$. More interestingly this was found to give higher initial rates of suction but which decreased very sharply over time due to the moisture-content dependent nature of the capillary potential [13]. It is hypothesised that since $n$ and $\bar{r}$ are interdependent in porous granular media, then a reduction in both (caused by changing PSD and/or compaction energy) would increase $\Psi$ (due to smaller $\bar{r}$ ) but reduce $\xi$ (due to lower porosity). Hence, the rate of flow reduction over time, as a result of $\Psi(\theta)$, is higher when changes to material pore structure result in $\Delta \theta_{c}$ being negative. The experimental data for SRE materials has been presented elsewhere [13, 21], and partly in Table 2 for comparison.

\section{$6 \quad$ Heat Transfer and Storage}

Within a porous building material, heat transfer can occur through a number of mechanisms (see Figure 6). Firstly, there is conduction, which occurs primarily through the material's granular skeleton, which in the case of SRE consists of hydraulically-bound mineral aggregate particles and clays. Heat transfer will be enhanced by the introduction of water into the voids 
between particles as the thermal conductivity of water is an order of magnitude higher than air, and conduction at inter-particle contact points is augmented by menisci formation. Localised radiative and convective heat transfer will also occur between particles within the matric structure and these are assumed to be included within the continuum-level moisture content dependent thermal conductivity, $\lambda^{*}(\mathrm{~W} / \mathrm{m} \mathrm{K})$ [11]. The dry state and moisturedependant thermal conductivity $\left(\lambda^{*}\right)$ were measured using a heat flow meter apparatus to ISO 8301 [11]. Moisture factor $\left(m_{f}\right)$ the slope of the $\lambda: S_{r}$ graph and was determined by linear regression, such that:

$$
\lambda^{*}=\lambda\left(1+S_{r} m_{f}\right)
$$

The moisture content-dependant specific heat capacity, $c_{p}{ }^{*}$ was calculated as the sum of the heat capacities of the constituent parts, weighted by their relative mass fractions, $\varpi$, as shown in Equation 2 [12, 22].

$$
\rho_{\text {bulk }} c_{p}^{*}=\rho_{\text {dry }}\left(\varpi_{\text {sand }} c_{\text {sand }}+\varpi_{\text {gravel }} c_{\text {gravel }}+\varpi_{\text {clay }} c_{\text {clay }}+\sigma_{\text {cem }} c_{\text {cem }}\right)+w c_{w}
$$

The results from these tests have previously been presented $[11,12]$ and are shown in Table 2 for direct comparison of all hygrothermal properties between each of the materials.

\section{$7 \quad$ Parametric analysis of hygrothermal properties}

Table 2 shows the hygrothermal functional properties for each of the three SRE materials. The parametric difference between each material is the particle size distribution which, since compaction energy and solid phase properties are constant, results in variation in packing efficiency and hence i) bulk porosity and, ii) void size distribution. Clearly dry density and bulk porosity are inversely related and so higher porosity results in reduced volumetric heat capacity $(C)$, but increases sorptivity $(S)$ and vapour permeance $(W)$. These broad trends are somewhat predictable, and the new data presented here can be used by other researchers in transient hygrothermal modelling of SRE materials. Interesting trends occur when one considers the intricacies of inter-particle contact, void size distribution and pore network 
tortuosity brought about by particle packing efficiency. Moisture factor $m_{f}$, for example, represents the sensitivity of a material's thermal conductivity to increasing degree of saturation and is not simply related to porosity $[11,12]$. Much more research is needed to understand how heat transfer occurs in porous granular materials.

Whilst the uncertainty in the measurements made for the tests were small (balance accurate to +/- 0.01g, stop watch accurate to 1s) and the test environments were closely controlled and monitored (temperature better than $+/-1^{\circ} \mathrm{C}$ and $\mathrm{RH}$ better than $+/-3 \%$ ), simply propagating these errors may underestimate the uncertainty of the results. Galbraith [23] has shown that, for identical materials, different laboratories can produce results that vary in excess of $+/-20 \%$ of the mean vapour permeability result for particle board. This was attributed to systematic error in the tests as evidenced by the large bias between individual laboratories. Assuming that the tests are carried out carefully, a confidence interval of $+/-5 \%$ should be achievable [23], however the properties of rammed earth specimens are known to vary between samples and wider variation may be expected (authors have found strength tests to typically vary by $+/-20 \%)$. Further testing is therefore required to determine the accuracy of the results, however, while the moisture storage function for the three materials described here may be deemed similar, it is reasonable to attribute significant differences in the permeability results.

The sorption isotherm in Figure 7 shows the wetting and drying curves for each of the three SRE materials. The point $\theta_{r}$ is difficult to measure experimentally since by definition it occurs at $\varphi \rightarrow 1$. Therefore, the important transitional point $\theta_{c}$ has been found and the portion of the isotherm shaded in grey (between $>95 \% \mathrm{RH}-100 \% \mathrm{RH}$ ) is interpolated for completeness. Although at scale the moisture storage curves are very similar a degree of hysteresis occurs between wetting and drying as a result of changes to the net capillary potential as described previously. The gradient of the linear section of the moisture storage curves is used to 
determine the hygroscopic moisture capacity for absorption (wetting), $\xi_{\mathrm{a}}$ and for desorption (drying), $\xi_{\mathrm{d}}$, the values for which are given in Table 2. A particular portion of the isotherm that is of interest in relation to building physics is that which occurs in the $\mathrm{RH}$ range that is defined as the indoor comfort zone, i.e. between 40 and 70\% RH [24].

Figure 8 highlights disparities that occur between the wetting/drying moisture storage curves for respective SRE materials where the indoor comfort range (above) is shaded. The total hygroscopic moisture storage capacity of SRE materials appears to vary by a small amount in relative terms. Interestingly, in terms of material functional properties the moisture storage capacity across the range appears to inversely relate to porosity. The 433 material, for example, exhibits the highest hygroscopic moisture storage capacity (across the range) and correspondingly the highest $\Psi(\theta)$, however this material also has the lowest porosity and vapour permeability. It is assumed that the surface properties of the solid phase material components are constant and since $\theta$ never approaches $\theta_{r}$ (always hygroscopic domain), the capacity for moisture vapour storage across a given $\mathrm{RH}$ range must be determined by the overlap between VSD and critical pore radii, as defined by Kelvin’s equation. This simple relationship, however, relies upon the significant assumption that porosity is a constant. In porous granular materials, PSD and compaction energy effectively determine the particle packing efficiency. Crucially this suggests that bulk porosity and mean pore radius $\bar{r}$ are interdependent variables for porous granular media; increasing packing efficiency will increase the vapour storage function whilst decreasing transfer rates (sorptivity and vapour permeability) and visa versa. The implications are that since VSD and $\bar{r}$ can be controlled by compaction energy and PSD, the hygrothermal functional properties of SRE materials can be designed using this technique, e.g. a 703 mix would sacrifice moisture storage capacity in favour of increased moisture transport rates. 
When considering the use of hygrothermal materials for relative humidity buffering in buildings it is important to consider the response rates of the material to changes in ambient relative humidity. Previous research has drawn direct comparisons between water vapour absorption rates $\left(\mathrm{g} / \mathrm{m}^{2} \mathrm{~s}\right)$ for different materials [25] with the premise that higher values indicate superior buffering ability. The fundamental weakness with this approach is that rather than buffering, this data provides the maximum rate since as moisture is absorbed i) the vapour pressure differential decreases (the driving force for absorption rate) towards zero as equilibrium is approached, and ii) the internal mass transfer rates slow down as $\theta$ increases. This relationship produces the characteristic w:t curve where $\Delta w \rightarrow 0$ as $\Delta P \rightarrow 0$ (thermodynamic equilibrium). Whilst it is not possible to use experimental data of individual functional properties to directly compare moisture buffering capacity between materials, hygrothermal transient models such as WUFI can simulate the effects of moisture buffering by coupling mass storage and diffusion functions, and then solving the mass balance equations.

\section{Conclusions}

Suitable experimental methodologies for determining the functional hygrothermal properties of SRE materials have been identified. Comparative experimental data has been presented for three different SRE mix designs enabling parametric analysis of the influence of these variables on hygrothermal properties. Higher bulk porosity corresponds to reduced volumetric heat capacity $(C)$, but increased sorptivity $(S)$ and vapour permeance $(W)$. Since bulk porosity and VSD are interdependent and are largely controlled by PSD and compaction energy, it follows that decreased porosity results in a decrease in $\bar{r}$ for a given material (constant PSD and particle geometry). This is consistent with experimental observations of increased capillary potential coupled with decreased permeability. The variation in vapour absorption capacity is consistent with the latter observation since capacity appears to increases with 
capillary potential and is inversely related to bulk porosity. However, at total hygroscopic storage capacity appears to vary little as a result of SRE mix parameters whereas response rates can vary significantly. This is perhaps the key to understanding the use of hygrothermal materials for relative humidity buffering in buildings because the fabric vapour storage capacity will typically be more than sufficient in relation to the volume of air inside a room. The opportunity for SRE materials to perform well in this regard is related to optimising their response rate to match the anticipated fluctuations in vapour pressure gradients. A fundamental understanding of hygrothermal behaviour can be combined with an understanding of the functional properties of hygrothermal materials, including experimental approaches to quantifying these properties. The next step is to verify this predictive approach by numerically simulating the hygrothermal behaviour of SRE walls under known indoor/outdoor climatic conditions and then comparing the predicted material responses with experimental measurements.

\section{Acknowledgements}

The authors wish to acknowledge the support of the Engineering and Physical Sciences Research Council.

\section{References}

1. Eartharchitecture.org. 2008. Earth Architecture. [online] Available at http://www.eartharchitecture.org/ [accessed 13 November 2008]

2. Building Research Institute of the University of Kassel. 2008. Facts. [online] Available at http://www.asl.uni-kassel.de/ feb/index.html [accessed 13 November 2008]

3. Mortenson N. 2000. The naturally air conditioned house. [online] Available at http://www.dab.uts.edu.au/ebrf/research/air_conditioned.html [accessed 13 November 2008]

4. Taylor P \& Luther MB. 2004. Evaluating rammed earth walls: a case study. Solar Energy, 76(1), pp. 79-84.

5. Jayasinghe C \& Kamaladasa N, 2007, 'Compressive strength characteristics of cement stabilized rammed earth walls’, Construction and Building Materials 21 [11] pp. 1971-1976 
6. Hall M, 2006, 'Assessing the Environmental Performance of Stabilised Rammed Earth Walls using a Climatic Simulation Chamber’, Building and Environment, 42 [1] pp.139-145

7. Heathcote KA, 1995, 'Durability of Earth Wall Buildings', Construction and Building Materials, 9[3] pp.185-189

8. Bryan AJ, 1988, 'Criteria for the Suitability of Soil for Cement Stabilisation', Building and Environment 23[4] pp.309-319

9. Bryan AJ, 1988, 'Soil/Cement as a Walling Material - I: Stress/Strain Properties', Building and Environment 23[4] pp.321-330

10. Innovative Pavement Research Foundation, 2005, Effects of Coarse Aggregate Clay-Coatings on Concrete Performance’, Technical Report IPRF-01-G-002-01-4.2, Skokie, Illinois

11. Hall M \& Allinson D, 2008, 'Assessing the Effects of Soil Grading on the Moisture Content-Dependent Thermal Conductivity of Stabilised Rammed Earth Materials', Applied Thermal Engineering, 29 pp. 740 747

12. Hall M \& Allinson D, 2008, 'Assessing the Moisture-Content Dependent Parameters of Stabilised Earth Materials Using the Cyclic-Response Admittance Method’, Energy and Buildings 40 [11] pp. 2044 - 2051

13. Hall M \& Allinson D, 2009, 'Influence of Cementicious Binder Content on Moisture Transport in Stabilised Earth Materials Analysed using 1-D Sharp Wet Front Theory, Building and Environment 44 pp. 688 - 693

14. Atkins P \& De Paula J, 2006, Atkins' Physical Chemistry - $8^{\text {th }}$ Edition, Oxford University Press

15. Kunzel H, 1995, 'Simultaneous heat and moisture transport in building components', Report based on PhD thesis, Fraunhofer Institute of Building Physics

16. Valen MS, 1998, Moisture Transfer In Organic Coatings On Porous Materials - The Influence Of Varying Environmental Conditions, PhD Thesis, Norwegian University of Science and Technology, Trondheim

17. BSI, 2000, BS EN ISO 12571:2000 Hygrothermal performance of building materials and products. Determination of hygroscopic sorption properties, British Standards Institute, London

18. BSI, 2001, BS EN ISO 12572:2001 Hygrothermal performance of building materials and products. Determination of water vapour transmission properties, British Standards Institute, London

19. Hall C \& Hoff WD, 2002, Water Transport in Brick, Stone and Concrete, Taylor \& Francis, London

20. Hall C \& Yau MHR, 1987, 'Water Movement in Porous Building Materials - IX: The Water Absorption and Sorptivity of Concretes', Building and Environment 22[1], pp. 77-82

21. Hall M \& Djerbib Y, 2005, "Moisture Ingress in Rammed Earth: Part 3 - The Sorptivity and the Surface Inflow Velocity”, Construction and Building Materials, 20 [6] pp.384-395 
450

451
22. Campbell GS \& Norman JM, 1998, An Introduction to Environmental Biophysics - 2nd Edition, Springer, New York

23. Galbraith GH, 1993, 'Vapour permeability: suitability and consistency of current test procedures’, Building services engineering research and technology 14 [2] pp. 67-70

24. CIBSE, 2006, Guide A: Environmental design $-7^{\text {th }}$ Edition, Chartered Institute of Building Services Engineers, London

25. Minke G, 1995, “Materialkennwerte Von Lehmbaustoffen”, Bauphysik, 17 pp. 124-130 
Figure Captions

459

460

Fig 1 - Water vapour sorption isotherm illustrating relative moisture contents and Kelvin Equation critical pore radii

Fig 2 - Capillary potential: relative moisture content graph with corresponding moisture domains

Fig 3 - Mechanisms of vapour diffusion in porous granular materials wetting/drying curves between SRE materials 


\begin{tabular}{lc}
\hline \multicolumn{1}{c}{ Salt solution } & RH (\%) at $\mathbf{2 3}^{\circ} \mathbf{C}$ \\
\hline Magnesium chloride & $32.90 \pm 0.17$ \\
\hline Potassium carbonate & $43.16 \pm 0.36$ \\
\hline Magnesium nitrate & $53.49 \pm 0.22$ \\
\hline Sodium bromide & $58.20 \pm 0.42$ \\
\hline Sodium chloride & $75.36 \pm 0.13$ \\
\hline Potassium nitrate & $94.00 \pm 0.60$ \\
\hline
\end{tabular}

475 
477 Table 2 - Hygrothermal properties of SRE mix recipes

\begin{tabular}{|c|c|c|c|c|c|c|c|c|c|c|c|}
\hline \multirow[b]{2}{*}{ mix } & \multirow[b]{2}{*}{$\rho_{d r y}$} & \multirow[b]{2}{*}{$n$} & \multicolumn{5}{|c|}{ Thermal Properties } & \multicolumn{4}{|c|}{ Hygric Properties } \\
\hline & & & $C$ & $\lambda$ & $m_{f}$ & \multicolumn{2}{|c|}{$\lambda *$} & $S$ & $W$ & $\xi_{\mathrm{a}}$ & $\xi_{d}$ \\
\hline & \multirow[t]{2}{*}{$\mathrm{kg} / \mathrm{m}^{3}$} & \multirow[t]{2}{*}{-} & \multirow[t]{2}{*}{$\mathrm{MJ} / \mathrm{m}^{3} \mathrm{~K}$} & \multirow[t]{2}{*}{$\mathrm{W} / \mathrm{m} \mathrm{K}$} & \multirow[t]{2}{*}{-} & \multicolumn{2}{|c|}{$\mathrm{W} / \mathrm{m} \mathrm{K}$} & \multirow[t]{2}{*}{$\mathrm{mm} / \min ^{0.5}$} & \multirow[t]{2}{*}{$\mathrm{kg} / \mathrm{m}^{2} \mathrm{sPa}$} & \multirow[t]{2}{*}{$\mathrm{kg} / \mathrm{kg}$} & \multirow[t]{2}{*}{$\mathrm{kg} / \mathrm{kg}$} \\
\hline & & & & & & $S_{r}=0$ & $S_{r}=1$ & & & & \\
\hline 433 & $2120^{a}$ & $0.239^{\mathrm{a}}$ & 1.754 & $1.010^{\mathrm{a}}$ & 0.802 & 1.010 & 1.820 & $1.487^{\mathrm{b}}$ & $1.56 \mathrm{E}^{-10}$ & 23.20 & 31.56 \\
\hline 613 & $2020^{a}$ & $0.273^{a}$ & 1.728 & $0.833^{a}$ & 0.643 & 0.833 & 1.369 & $2.117^{b}$ & $3.23 \mathrm{E}^{-10}$ & 28.71 & 19.19 \\
\hline 703 & $1980^{a}$ & $0.302^{\mathrm{a}}$ & 1.719 & $0.866^{\mathrm{a}}$ & 0.955 & 0.866 & 1.693 & $2.700^{b}$ & $4.79 \mathrm{E}^{-10}$ & 13.93 & 21.30 \\
\hline 478 & $\mathrm{a}[8]$ & & & & & & & & & & \\
\hline 479 & $\mathrm{~b}$ [10] & & & & & & & & & & \\
\hline
\end{tabular}

